\title{
Effect of Feeding on the Chemical Control of Breathing in the Newborn Infant
}

\author{
M. DURAND, F. N. LEAHY, M. MACCALlum, D. B. CATES, H. RIGATTO, AND V. CHERNICK (24)
}

Department of Pediatrics, University of Manitoba, Winnipeg, Manitoba, Canada

\begin{abstract}
Summary
To examine the influence of feeding on the chemical control of breathing in neonates, we studied the ventilatory response to $3 \%$ $\mathrm{CO}_{2}$ in air in nine bottle fed (BOT) and eight breast fed (BR) term infants during feeding while the infants were alert. Control responses were obtained either before or after feeding. $\dot{V}_{E}$, respiratory frequency, tidal volume, inspiratory time, expiratory time, and sum of inspiratory and expiratory time, $\mathrm{V}_{\mathrm{T}} / \mathrm{Ti}, \mathrm{Ti} / \mathrm{T}_{\text {tot }}, \mathrm{PACO}_{2}$ and slope (S) of $\mathrm{CO}_{2}$ response (liter $/ \mathrm{min} / \mathrm{kg} / \mathrm{mmHg}$ ) were determined. During 3\% $\mathrm{CO}_{2}$ while resting $\mathrm{BR}$ had a lower $\dot{\mathrm{V}}_{\mathrm{E}}, \mathrm{V}_{\mathrm{T}}, \mathrm{V}_{\mathrm{T}} /$ $T i$ than BOT and $S$ in BR was $40 \%$ of BOT $(P<0.05)$. During feeding and $\mathrm{CO}_{2}$ when compared to resting and $\mathrm{CO}_{2}$ there was no difference in either BR or BOT in $V_{T} / T i$ but Ti/T $T_{\text {tot }}$ decreased in both groups. During feeding, $\mathrm{S}$ in BOT was reduced from 0.049 \pm 0.012 (mean \pm S.E.) to $0.013 \pm 0.002$ (74\% reduction) and in BR from $0.020 \pm 0.002$ to $0.009 \pm 0.002$ (55\%). Thus, behavioral activity (either BR or BOT) markedly depresses the ventilatory response to chemical stimuli $\left(\mathrm{CO}_{2}\right)$. This modification is primarily related to changes in "effective" respiratory timing $\left(\mathrm{Ti} / \mathrm{T}_{\text {tot }}\right)$ rather than mean inspiratory flow $\left(V_{T} / T i\right)$.
\end{abstract}

\section{Speculation}

This is the first demonstration in the newborn infant that behavioral activity (feeding) can override the usual ventilatory control mechanisms. The precise mechanism is unknown and requires further study.

Breathing is controlled by two functionally integrated elements: the behavioral (voluntary) control system, which originates in the forebrain, is involved in activities such as phonation; and the metabolic (automatic) respiratory control system, centered in the brain stem $(2,12)$. Studies in healthy adult subjects have shown that during normal speech there is a marked disruption of the ventilatory response to $\mathrm{CO}_{2}(3,15)$, suggesting that during phonation there is a relaxation or overriding of metabolic respiratory control. The influence of behavioral activity on the chemical control of breathing in neonates has not been studied. We designed this study, therefore, to examine the interaction of the metabolic and behavioral respiratory control systems, by comparing the ventilatory response to $\mathrm{CO}_{2}$ in bottle fed and breast fed infants while resting and during feeding.

\section{MATERIALS AND METHODS}

We studied nine bottle fed healthy term infants (BOT): birth weight (mean \pm S.E.) $3.15 \pm 0.15 \mathrm{~kg}$; gestational age $39.2 \pm 1.0$ wk; postnatal age $6.4 \pm 2.4$ days; and 8 breast fed healthy term infants (BR); birth weight $3.35 \pm 0.14 \mathrm{~kg}$; gestational age $39.8 \pm$ $0.3 \mathrm{wk}$; postnatal age $4.2 \pm 0.7$ days. There were five males and four females in the BOT group, and five males and three females in the BR group. The study was explained to the parents of each subject and informed consent obtained.

A nosepiece with a constant background flow and a screen flowmeter was used to record flow, tidal volume, end-tidal $\mathrm{CO}_{2}$ and $\mathrm{O}_{2}$ concentrations, according to methods described in detail previously $(18,19)$, and recording was done with a Gould Brush 480 Recorder. The ventilatory response to $3 \% \mathrm{CO}_{2}$ in air was assessed before or after feeding (resting) and during feeding in the BOT group, while the infants were alert. Alertness was defined by open eyes for more than $2 \mathrm{~min}$ and presence of purposeful movements. For BR it was only possible to obtain control responses after feeding in all but one infant. $\dot{\mathrm{V}}_{E}$, respiratory frequency $(f)$, tidal volume $\left(V_{T}\right)$, inspiratory time $(\mathrm{Ti})$, expiratory time (Te), sum of inspiratory and expiratory time $\left(\mathrm{T}_{\text {tot }}\right), \mathrm{V}_{\mathrm{T}} / \mathrm{Ti}$, $\mathrm{Ti} / \mathrm{T}_{\text {tot }}, \mathrm{PACO}_{2}$ and slope of $\mathrm{CO}_{2}$ response (liter $/ \mathrm{min} / \mathrm{kg} / \mathrm{mmHg}$ ) were determined $(1,6,11)$. The ventilatory response to $\mathrm{CO}_{2}$ was analyzed by measuring and summing each tidal volume during 1 min periods, before and during the fifth min following $\mathrm{CO}_{2}$ administration. End-tidal $\mathrm{PCO}_{2}$ was estimated during the same time interval and assumed to be equivalent to alveolar $\mathrm{PCO}_{2}$. Ti and $\mathrm{Te}$ were measured for each breath from the flow tracing during the same time interval that minute ventilation $\left(\dot{V}_{E}\right)$ was measured. The fifth min was chosen for analysis because previous work from this laboratory has shown that a steady state has been achieved by neonates during this time interval $(4,9,20)$.

Infants were clothed and bundled as is usual for term infants. Bottle fed neonates were fed by a nurse and breast fed infants by their own mothers, in the usual feeding position. All tolerated the procedure well and did not seem to be disturbed during the study. Statistical significance of the differences was assessed using the paired $t$ test for feeding versus not feeding values and the unpaired $t$ test for bottle versus breastfeeding values.

\section{RESULTS}

Effect of feeding on the ventilatory response to $\mathrm{CO}_{2}$. During feeding, the slope of $\mathrm{CO}_{2}$ response (mean \pm S.E.) in BOT infants was reduced by $74 \%$ from $0.049 \pm 0.012$ to $0.013 \pm 0.002$ liter/ $\mathrm{min} / \mathrm{kg} / \mathrm{mmHg}(P<0.01)$ when compared to the resting $\mathrm{CO}_{2}$ response. In $\mathrm{BR}$ infants the slope was also reduced during feeding, from $0.020 \pm 0.002$ to $0.009 \pm 0.002(P<0.01)$, representing a $55 \%$ reduction. Thus, while feeding, there was a pronounced decrease in the ventilatory response to $\mathrm{CO}_{2}$ in both groups of infants (Fig. 1 and 2). The slope of the $\mathrm{CO}_{2}$ response during feeding was not significantly different for the BOT and BR groups. The significant decrease in $\dot{\mathrm{V}}_{\mathrm{E}}$ with $\mathrm{CO}_{2}$ during feeding when compared to the resting state plus $\mathrm{CO}_{2}$ was accounted for by a significant decrease in $\mathrm{V}_{\mathrm{T}}$ in both groups (Fig. 3). There was no significant effect of feeding on respiratory frequency (f) (Fig. 4). Because of this decrease in $\dot{\mathrm{V}}_{\mathrm{E}}, \mathrm{PACO}_{2}$ was greater with $\mathrm{CO}_{2}$ during feeding than during rest by $2.8 \mathrm{mmHg}$ in the $\mathrm{BF}$ group and $3.6 \mathrm{mmHg}$ in the BOT group $(P<0.05)$.

Effect of feeding on mean inspiratory flow $\left(V_{T} / T i\right)$. While resting, the addition of $\mathrm{CO}_{2}$ increased $\mathrm{V}_{\mathrm{T}} / \mathrm{Ti}$ (mean inspiratory flow) from $38.2 \pm 3.3 \mathrm{ml} / \mathrm{sec}$ to $63.2 \pm 4.3 \mathrm{in} \mathrm{BOT}$ and from $31.8 \pm 3.1$ to $43.4 \pm 4.2$ in BR $(P<0.05)$ (Fig. 5). During feeding, the addition of $\mathrm{CO}_{2}$ also increased $\mathrm{V}_{\mathrm{T}} / \mathrm{Ti}$ from $48.6 \pm 3.0 \mathrm{ml} / \mathrm{sec}$ to $63.8 \pm 4.1$ in BOT and from $34.4 \pm 5.2$ to $44.8 \pm 5.0$ in BR $(P<0.05)$. There 
BOTTLE FED

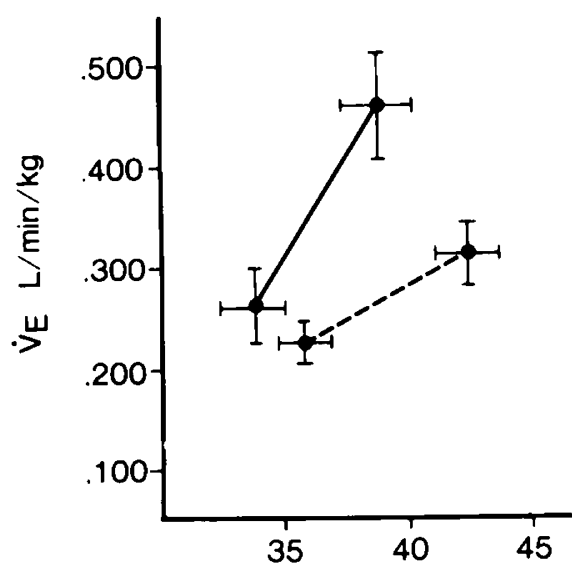

BREAST FED

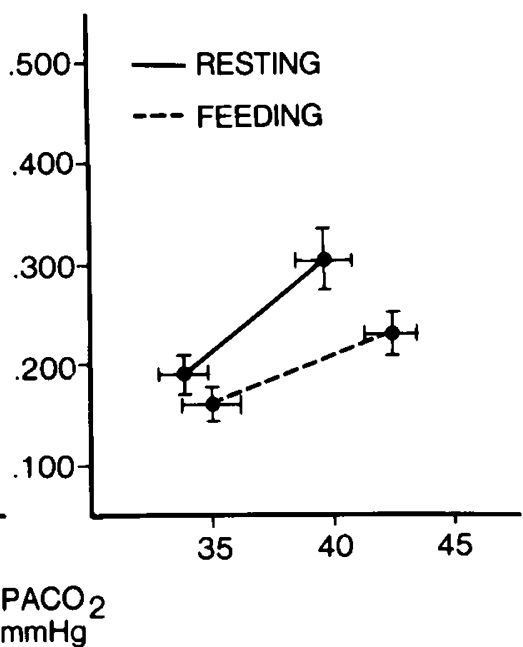

Fig. I. $\dot{\mathrm{V}}_{\mathrm{E}}$ in bottle and breast fed infants plotted against $\mathrm{PACO}_{2}$ during resting and feeding, and after the addition of $3 \%$ inspired $\mathrm{CO}_{2}$.

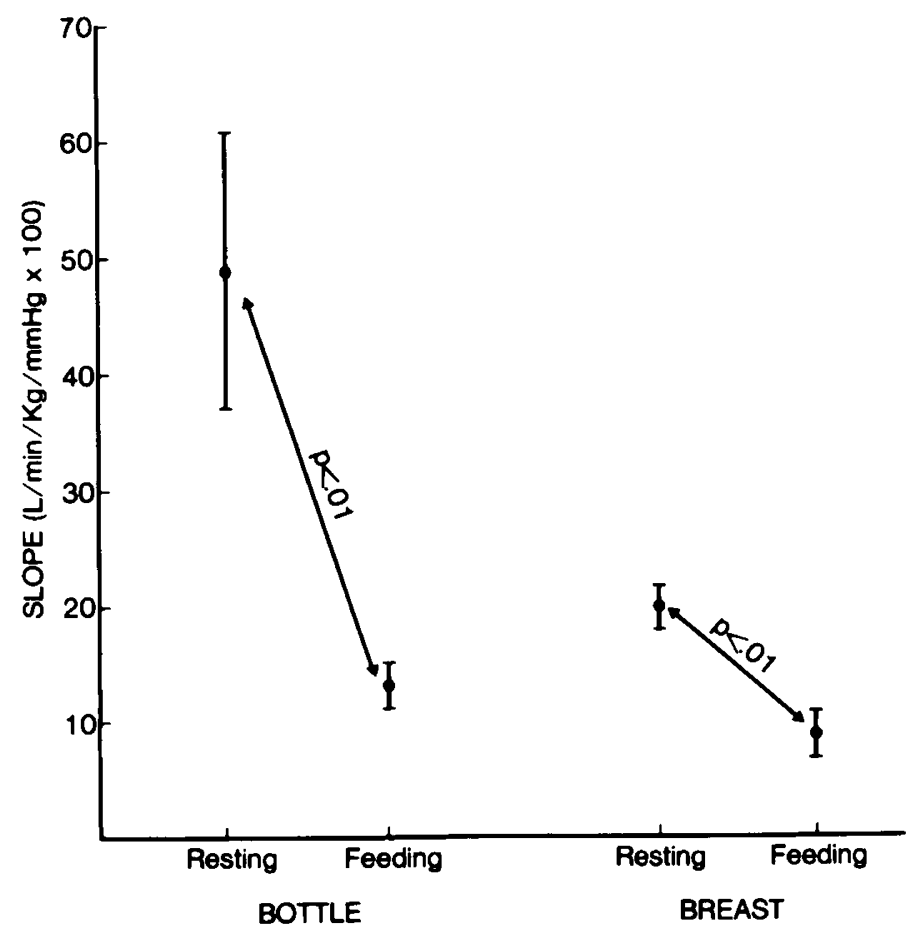

Fig. 2. Slope (S) of $\mathrm{CO}_{2}$ response in bottle fed and breast fed infants during resting and during feeding.

was no difference in $\mathrm{V}_{\mathrm{T}}$ / Ti during feeding plus $\mathrm{CO}_{2}$ when compared to resting plus $\mathrm{CO}_{2}$ for either the BOT or BR groups.

Effect of feeding on "effective" respiratory timing $\left(T i / T_{\text {tot }}\right)$. During feeding and $\mathrm{CO}_{2}$ when compared with resting and $\mathrm{CO}_{2}$, the $\mathrm{Ti} / \mathrm{T}_{\text {tot }}$ decreased significantly from $0.384 \pm 0.018$ to $0.311 \pm 0.019$ $(P<0.05)$ in the BOT group and from $0.399 \pm 0.018$ to $0.303 \pm$ $0.017(P<0.05)$ in the BF group (Fig. 6). The decrease in $\mathrm{Ti} / \mathrm{T}_{\text {tot }}$ was entirely accounted for by a decrease in $\mathrm{Ti}$ since $\mathrm{T}_{\text {tot }}$ did not change significantly. Thus, the major effect of feeding on the ventilatory response to $\mathrm{CO}_{2}$ was an early termination of inspiration.

Effect of the type of feeding (BOT and BR) on ventilation. Interestingly, the BOT group had a significantly greater control response (in the absence of feeding) to $\mathrm{CO}_{2}$ than did the $\mathrm{BF}$ group $(P<0.05)$ (Fig. 1). The slope of BF infants was $40 \%$ of the BOT group and was accounted for by a significantly lower $\dot{V}_{E}, V_{T}$ and $\mathrm{V}_{\mathrm{T}} / \mathrm{Ti}$ in response to $\mathrm{CO}_{2}(P<0.05)$, despite comparable values before $\mathrm{CO}_{2}$ was added (Figs. 2, 3, 5). The control response curves

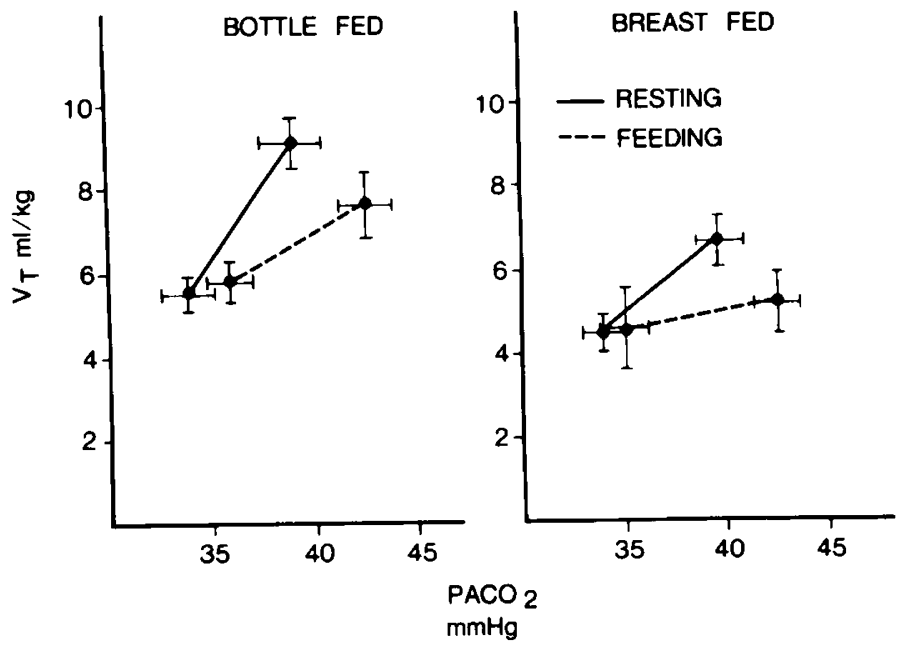

Fig. 3. $\mathrm{V}_{\mathrm{T}}$ versus $\mathrm{PACO}_{2}$. During $\mathrm{CO}_{2}$ administration, $\mathrm{V}_{\mathrm{T}}$ significantly decreased during feeding when compared to rest.

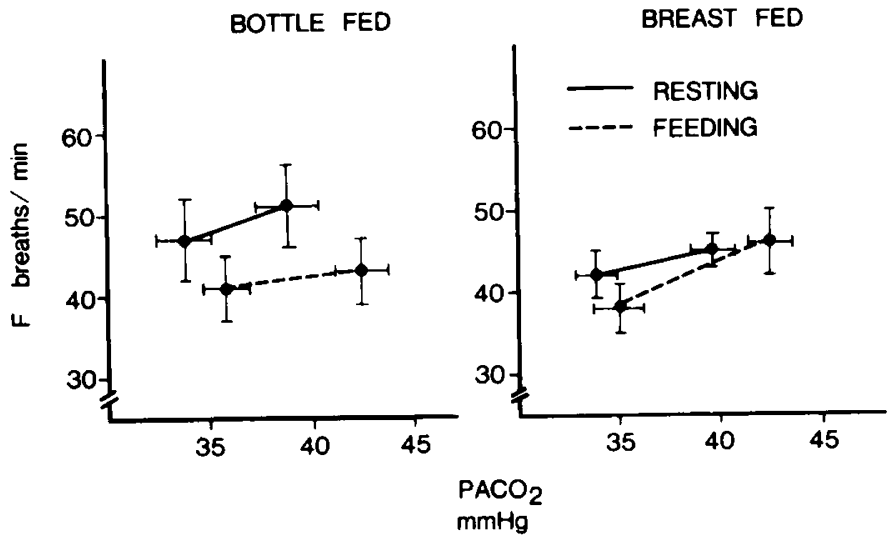

Fig. 4. $\mathrm{f}$ versus $\mathrm{PACO}_{2}$. There is no significant effect of feeding on respiratory frequency in either group of infants.

for the BF group in seven of eight instances were obtained after feeding. In the six BOT infants studied before feeding, $\mathrm{S}$ was 0.058 $\pm 0.016 \mathrm{liter} / \mathrm{min} / \mathrm{kg} / \mathrm{mmHg}$ and in the three infants studied after feeding $S$ was $0.031 \pm 0.011(P>0.1)$. Despite the fact that these slopes are not significantly different, the differences seen between $B R$ and BOT slopes in the absence of feeding may not be valid because only one infant in BR was studied before feeding. 


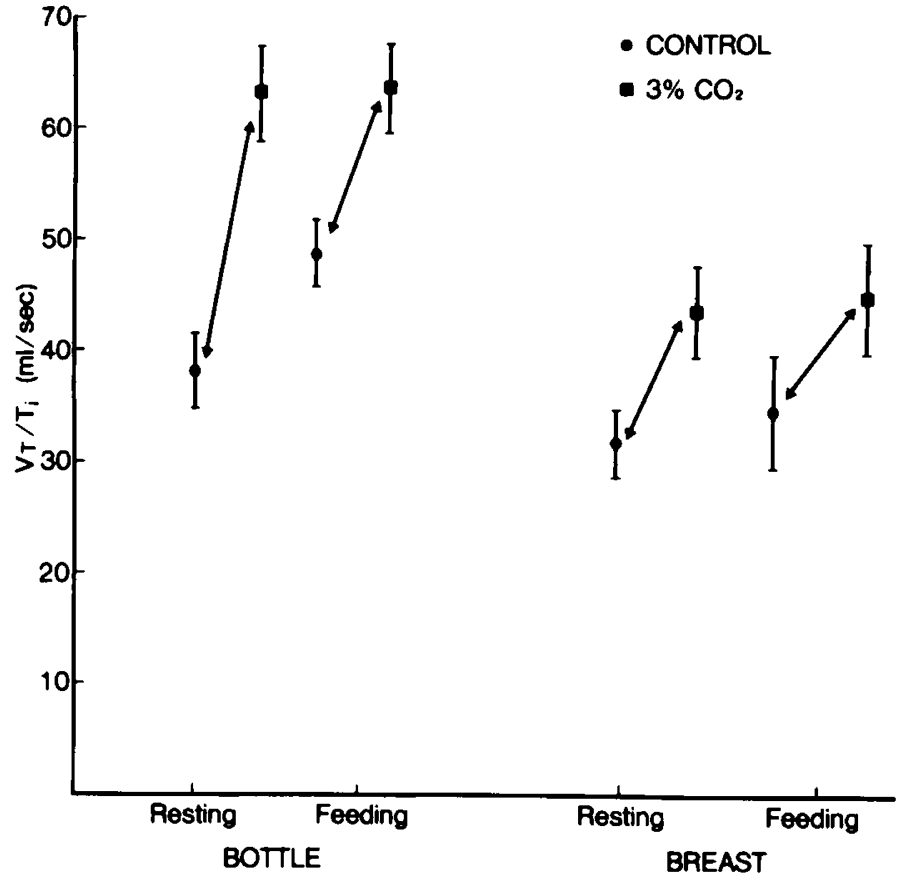

Fig. 5. Changes in $\mathrm{V}_{\mathrm{T}} / \mathrm{Ti}$ with $\mathrm{CO}_{2}$ administration during rest and feeding in bottle and breast fed infants.

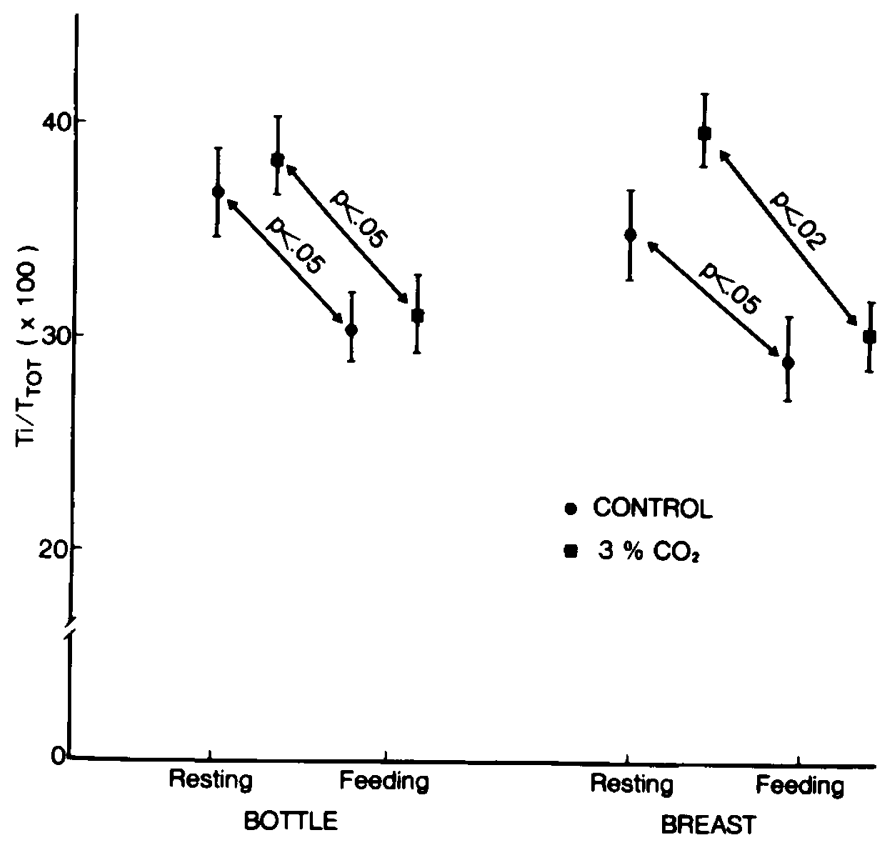

Fig. 6. Changes in $\mathrm{Ti} / \mathrm{T}_{\text {tot }}$ with $\mathrm{CO}_{2}$ administration during rest and feeding in bottle and breast fed infants.

During feeding, in the absence of $\mathrm{CO}_{2}$, BOT had a greater reduction in $\mathrm{Ti}$ than $\mathrm{BR}(0.37 \pm 0.02 \mathrm{sec}$ versus $0.45 \pm 0.05 ; P<$ 0.05 ). Thus, $\mathrm{V}_{\mathrm{T}} / \mathrm{Ti}$ increased significantly in BOT in the absence of $\mathrm{CO}_{2}$ from $38.2 \pm 3.3$ to $48.6 \pm 3.0 \mathrm{ml} / \mathrm{sec}(P<0.05)$ but no significant change occurred in the BF group (Fig. 5).

\section{DISCUSSION}

While the metabolic respiratory control system is involved primarily in acid-base and oxygen homeostasis, the behavioral control system is involved in activities such as phonation $(10,12)$. Feeding also uses the ventilatory apparatus for nonrespiratory functions and is a necessary behavioral activity of normal newborn infants. In an earlier study on adults, Bunn and Mead (3) showed that during phonation minute ventilation $\left(\dot{\mathbf{V}}_{E}\right)$ increases slightly, and the ventilatory response to hypercapnia was diminished. Phillipson et al. (15) demonstrated in adult subjects that even for degrees of hypercapnia considerably higher than might be encountered during speech, the behavioral respiratory control system can effectively override the metabolic system without there being a conscious effort to underbreathe or hold the breath. The present study extends these earlier observations to human neonates and demonstrates that during feeding there is a marked reduction in the ventilatory response to $\mathrm{CO}_{2}$. Interestingly, this reduction in the slope of $\mathrm{CO}_{2}$ response was greater in BOT neonates $(74 \%)$ when compared with BF infants (55\% reduction). However, this difference is accounted for by the higher control slope in the BOT group because the slopes during sucking were not different. The BF group had a lower $\dot{\mathrm{V}}_{\mathrm{E}}$ but the same $\mathrm{PACO}_{2}$ as the BOT fed group suggesting that there was a greater metabolic rate in the BOT group. Alternatively, feeding artificial formula which has a greater protein content than breast milk might decrease total buffer base and thus alter $\mathrm{CO}_{2}$ response. Unfortunately, arterial $\mathrm{pH}$ measurements were not done.

It is possible that the large reduction in slope may be in part related to changes in lung mechanics, due to feeding $(14,17,21)$. The control responses to $\mathrm{CO}_{2}$ were obtained in a random manner either before or after feeding in BOT infants and there was no difference in $\mathbf{S}$ done before or after feeding. Indeed seven out of eight control studies were done after feeding in the BF group and yet $\mathbf{S}$ during feeding was significantly reduced. Thus, mechanical factors cannot account for the reduction of $S$ during feeding. The reduction in $\mathrm{CO}_{2}$ response during feeding is comparable to decreases reported in adults during phonation $(3,15)$.

The major effect of feeding was an early termination of inspiration ( $\mathrm{Ti}$ was markedly reduced), whereas $T_{\text {tot }}$ remained unchanged. The precise mechanism for this effect is unknown. $V_{T}$ was also reduced during feeding plus $\mathrm{CO}_{2}$ and $\mathrm{V}_{\mathrm{T}} / \mathrm{Ti}$ did not change, indicating that mean inspiratory flow is maintained during functional interaction between the behavioral and metabolic control systems.

It is possible that during feeding, shortening of $\mathrm{Ti}$ is the primary event leading to a decrease in $V_{T}$, decrease in $\dot{V}_{E}$ and eventual reduction in $\mathrm{CO}_{2}$ response. Despite this, there is some response to $\mathrm{CO}_{2}$ since $\mathrm{V}_{\mathrm{T}} / \mathrm{Ti}$ increases with the addition of $\mathrm{CO}_{2}$ during feeding to the same value as that found in the absence of feeding. This response is somewhat different than that found in the adult during phonation since Phillipson et al. (15) reported that $\mathrm{V}_{\mathrm{T}} / \mathrm{Ti}$ did not change during phonation with the addition of $\mathrm{CO}_{2}$.

Whether or not the above changes are mediated through reflexes in the airways or esophagus during feeding remains to be determined. For instance, sucking might potentiate the inspiratory inhibitory pulmonary reflex $(8,13)$. Alternatively, intrinsic changes in the rhythmicity of the respiratory center during feeding could account for the reduced response to $\mathrm{CO}_{2}$ because the changes in ventilation during sucking appear to be related to the motor activity involved in feeding. In support of this notion is the demonstration in adult subjects that the $\mathrm{CO}_{2}$ response was unaffected by quiet reading without vocalization and decreased by reading aloud (15). In addition, gustatory activity is modulated by the hypothalamus and hypothalamic impulses are known to modify neuronal firing in the nucleus of the tractus solitarius. More specifically, studies in rats have demonstrated the presence of descending input from the lateral hypothalamic area-medial forebrain bundle to brain stem neurons possibly involved in oropharyngeal sensation and gustatory evoked phenomena (2). We are not aware of studies in the neonatal animal of the effect of hypothalamic stimulation on ventilatory responses.

The effect of feeding on the chemical control of breathing in neonates in different sleep states has not been studied, although several recent reports $(4,7,9,16)$ suggest that $\mathrm{CO}_{2}$ response is not different when comparing REM versus non-REM sleep. Our subjects were studied while alert, both before and after feeds and it seems unlikely that different states of consciousness can explain the results.

Interestingly, there was a difference in respiratory pattern during feeding in the absence of $\mathrm{CO}_{2}$ between BR and BOT. $\mathrm{V}_{\mathrm{T}} / \mathrm{Ti}$ 
increased significantly during feeding before $\mathrm{CO}_{2}(P<0.05)$ in the BOT group whereas in the BR group feeding alone did not change $V_{T} / T i$. The increase in $V_{T} / T_{i}$ in BOT was entirely accounted for by a reduction in $T i$ since $V_{T}$ did not change. Thus, bottle feeding alone significantly alters $\mathrm{Ti}$ and hence mean inspiratory flow compared to breast feeding and this could be related to the very different motor activity associated with feeding between the two groups $(5,22)$.

In summary, our findings indicate that feeding (either BR or BOT) markedly depresses the ventilatory response to chemical stimuli $\left(\mathrm{CO}_{2}\right)$. This modification is primarily related to changes in "effective" respiratory timing $\left(\mathrm{Ti} / \mathrm{T}_{\mathrm{tot}}\right)$ rather than mean inspiratory flow $\left(\mathrm{V}_{\mathrm{T}} / \mathrm{Ti}\right)$. The specific mechanism for this interaction between the behavioral and automatic ventilatory control systems is unknown.

\section{REFERENCES AND NOTES}

1. Avery, M. E., Chernick, V., Dutton, R. E., and Permutt, S.: Ventilatory response to inspired carbon dioxide in infants and adults. J. Appl. Physiol., 18: 895 (1963).

2. Bereiter, D., Berthoud, H. R., and Jeanrenaud, B.: Hypothalamic input to brain stem neurons responsive to oropharyngeal stimulation. Exp. Brain Res., 39: 33 (1980).

3. Bunn, J. C. and Mead, J.: Control of ventilation during speech. J. Appl. Physiol., 31: 870 (1971)

4. Davi, M., Sankaran, K., MacCallum, M., Cates, D., and Rigatto, H.: Effect of sleep state on chest distortion and on the ventilatory response to $\mathrm{CO}_{2}$ in neonates. Pediatr. Res., 13: 982 (1979).

5. Drewett, R. F. and Wolridge, M.: Sucking patterns of human babies on the breast. Early Human Development 3: 315 (1979).

6. Grunstein, M. M., Younes, M. and Milic-Emili, J.: Control of tidal volume and respiratory frequency in unanesthetized cats. J. Appl. Physiol., 35: 463 (1973).

7. Guthrie, R. D., Standaert, T. A., Hodson. W. A., and Woodrum, D. E.: Sleep and maturation of eucapnic ventilation and $\mathrm{CO}_{2}$ sensitivity in the premature primate. J. Appl. Physiol., 48: 347 (1980).

8. Hagan, R., Bryan, A. C., Bryan, M. H., and Gulston, G.: Neonatal chest wall afferents and regulation of respiration. J. Appl. Physiol., 42: 362 (1977).

9. Kalapesi, Z., Durand, M., Leahy, F. M., Cates, D. B., MacCallum, M., and
Rigatto, $\mathbf{H}$.: Effect of respiratory pattern on the ventilatory response to low concentrations of $\mathrm{CO}_{2}$ in preterm infants during sleep. Am. Rev. Respir. Dis. (submitted for publication).

10. Klatt, D. H., Stevens, K. N., and Mead. J.: Studies of articulatory activity and air flow during speech. Ann. N.Y. Acad. Sci., 155: 42 (1968).

11. Milic-Emili, J.: Recent advances in the evaluation of respiratory drive. Internat. Anesthesiol. Clin., 15: 39 (1977).

12. Mitchell, R. A. and Berger, A. J.: Neural regulation of respiration. Am. Rev. Respir. Dis., 111: 206 (1975)

13. Paintal, A. S.: Vagal sensory receptors and their reflex effects. Physiological Reviews, 53: 159 (1973).

14. Patel, B. D., Dinwiddie, R., Kumar, S. P., and Fox, W. W.: The effects of feeding on arterial blood gases and lung mechanics in newborn infants recovering from respiratory disease. J. Pediatr., 90: 435 (1977).

15. Phillipson, E. A., McClean, P. A., Sullivan, C. E., and Zamel, N.: Interaction of metabolic and behavioral respiratory control during hypercapnia and speech. Am. Rev. Respir. Dis., 117: 903 (1978).

16. Phillipson, E. A.: Control of breathing during sleep. Am. Rev. Respir. Dis., 1/8: 909 (1978).

17. Pitcher-Wilmott, R., Shutack, J. G., and Fox, W. W.: Decreased lung volume after nasogastric feeding of neonates recovering from respiratory disease. $J$. Pediatr., 95: 119 (1979).

18. Rigatto, $H$. and Brady, J. P.: A new nosepiece for measuring ventilation in preterm infants. J. Appl. Physiol., 32: 423 (1972).

19. Rigatto, H. and Brady, J. P.: Periodic breathing and apnea in preterm infants. I. Evidence for hypoventilation possibly due to central respiratory depression. Pediatrics, 50: 202 (1972).

20. Rigatto, H., Brady, J. P., and de la Torre Verduzco, R.: Chemoreceptor reflexes in preterm infants. II. The effect of gestational and postnatal age on the ventilatory response to inhaled carbon dioxide. Pediatrics, 55: 614 (1975).

21. Russell, G. and Feather, E. A.: Effect of feeding on respiratory mechanics of healthy newborn infants. Arch. Dis. Child., 45: 325 (1970).

22. Wolff, P. H.: The serial organization of sucking in the young infant. Pediatrics, 42: 943 (1968).

23. The authors thank Ms. Nancy Connell, Penny Trudel and Carol Picard for secretarial assistance in the preparation of the manuscript.

24. Requests for reprints should be addressed to: Dr. V. Chernick, Department of Pediatrics, Room S012, Medical College, 770 Bannatyne Avenue, Winnipeg. Manitoba, Canada, R3E OW3.

25. This research was supported by Medical Research Council of Canada and the Children's Hospital of Winnipeg Research Foundation, Inc.

26. Received for publication March 24, 1981.

27. Accepted for publication June 10, 1981. 